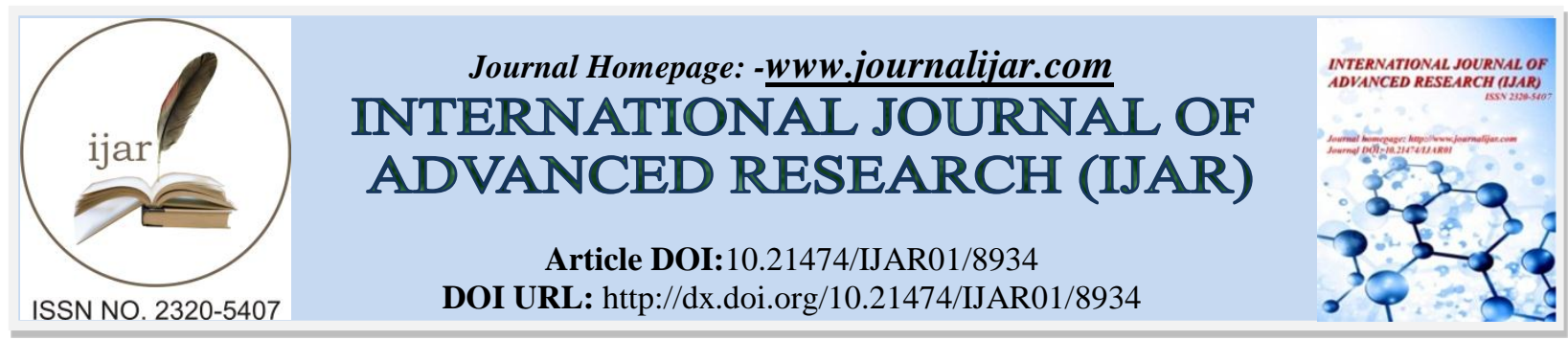

RESEARCH ARTICLE

\title{
E-LEARNING: ADAPTING TO RAPID PEDAGOGICAL CHANGES.
}

\section{Bryan Irvin J. Lamarca ${ }^{1}$, Mia V. Villarica ${ }^{2}$ and Shaneth Ambat ${ }^{3}$.}

1. University of Northern Philippines, Heritage City of Vigan, Ilocos Sur, Philippines.

2. Laguna State Polytechnic University,Santa Cruz, Laguna, Philippines.

3. FEU Institute of Technology, Sampaloc, Manila, Philippines.

\section{Manuscript Info}

Manuscript History

Received: 22 February 2019

Final Accepted: 24 March 2019

Published: April 2019

Key words:-

e-learning platform implementation, perceptions and awareness, web technologies.

\section{Abstract}

A model for the mathematical description of diffusion process is presented through this work and an attempt is also made for the applicability of Green's function method for solving the one dimensional diffusion equation within the desired limits. From this process the required solution to this diffusion equation by considering the initial condition $t=0$ will be obtained. This equation describes the rate of change of concentrations of substances to its own lattice or may be in different substances with a constant diffusion coefficient. At last a computational approach will also be used for getting the numerical solutions. While solving the equation we throughout consider $\mathrm{t}=0$, so that the result may also be applicable in an isothermal diffusion.

Copy Right, IJAR, 2019,. All rights reserved.

\section{Introduction:-}

Since 2004, there has been no innovation in the core Learning Management System (LMS) product; the cost of LMS have increased in a dramatic fashion and will continue to increase; and according to research conducted in the last quarter of 2010, the LMS market has settled around Moodle, Sakai, Blackboard, Desire2Learn, and eCollege. These are key LMS trends to note from the 2010 Campus Computing Survey.

For many academic institutions, the LMS is the most substantial tool used for education. The LMS is the means by which course information is distributed to students, and serves and supports the academic mission and strategic goals of universities. It is not common for the University of Northern Philippines (UNP) to periodically review existing information systems, particularly the UNP LMS, a Claroline platform that has been in use for six years now. The preceding conditions spawned the essential spur for the university to review its current e-learning implementation and the notion of necessity to adapt to rapid pedagogical changes that an LMS can handle. This research addresses the question, "To support the university's teaching and learning goals, should the university maintain its LMS or should it opt to adapt a new one?"

The purpose of this study was to (a) determine UNP instructors' and students' attitudes towards two e-learning implementations: UNP LMS and Moodle - the current product leading in the marketand (b) assess instructors' and students' awareness and usage of web technologies that can be used as tools in higher education. The results will be used in determining what e-learning platform to implement and will serve as basis for improving e-learning policies and guidelines.

Corresponding Author:-Bryan Irvin J. Lamarca.

Address:-University of Northern Philippines, Heritage City of Vigan, Ilocos Sur, Philippines. 


\section{Method:-}

\section{Participants}

The population of the study consists of 5 faculty, 31 Bachelor of Science in Computer Science Students, and 33 Bachelor of Science in Information Technology students. Random sampling was utilized in determining the sample size.

\section{Materials:-}

The study employs a quantitative (questionnaire) research design. The questionnaire was adapted from Raga et al. (2014). It assess the implementation of e-learning and the awareness and the usage of web technologies that can be used as tools in higher education. Chi square was used in determining the significant difference between the opinions of instructors and students on both e-learning implementations.

\section{Procedure}

The research was conducted at the College of Communication and Information Technology (CCIT) of UNP due to the following reasons: (a) the college is supposedly the entity that oversees technology in aiding/solving pedagogical problems with the use of technology; and (b) the UNP LMS usage was first implemented at the said college.

\section{Results:-}

Outlook differences.

As gleaned on Table 1, the implementation and tools awareness of UNP LMS garnered Chi-Square Values of 40.96 and 400.49 respectively which elicited significant differences in outlook between instructors and studentswith regards to theUNP LMS implementation and web technologies tools. Instructors and students have differences in opinion with regards on the implementation of Moodle (32.91). However, Table 1 shows that the tools awareness (103.00) exhibits significant differences on outlook between instructors and students.

\begin{tabular}{|l|l|l|l|l|}
\hline E-learning Platform & Components & Chi-Square value & Chi-Square Sig & Decision \\
\hline \multirow{2}{*}{ UNP LMS } & Implementation & $40.957^{*}$ & .031 & Reject Ho \\
\cline { 2 - 5 } & Tools & $400.49^{* *}$ & .000 & Reject Ho \\
\hline \multirow{2}{*}{ Moodle } & Implementation & 32.91 & .083 & Do not Reject Ho \\
\cline { 2 - 5 } & Tools & $103.00^{* *}$ & .000 & Reject Ho \\
\hline Note: *Significant at .05, **Significant at .01 & \multicolumn{2}{|l}{} \\
\hline
\end{tabular}

Table 1:-Chi Square computation for UNP LMS and Moodle

\begin{tabular}{|l|l|l|l|}
\hline Components & Chi-Square value & Chi-Square Sig & Decision \\
\hline Implementation & $102.96^{* *}$ & .000 & Reject Ho \\
\hline Tools & $579.65^{* *}$ & .000 & Reject Ho \\
\hline \multicolumn{2}{|l|}{ Note: $*$ Significant at $.05, * *$ Significant at .01} & \\
\hline
\end{tabular}

Table 2:-Overall difference in opinion between instructors and students on both platform implementations

Overall, both faculty and students have significant differences in opinion (as shown in Table 2) on the implementation (102.96) between the UNP LMS and Moodle.

\section{UNP LMS.}

Both instructors and students have a very high regardon the UNP LMS in the following: helping to support and improve communication between faculty and students $(\bar{x}=4.37)$; and enhancing the knowledge and understanding that students gain from lectures, tutorials, and practice $(\bar{x}=4.28)$. However, they have an average rating with regards to the UNP LMS being utilized by technology-savvy students only $(\bar{x}=3.25)$ and as a learning environment prohibiting students from developing their social skills $(\bar{x}=3.01)$.

As shown in Table 3, most studentsare aware of Syndication tools(81.3\%), and Social Bookmarking tools (76.6\%). However, it seems that least amount of students are aware of Social Networking (18.8\%) tools.Most students in the college use Social Networking (90.6\%) and Instant Messaging and Chat (81.3\%). For the teachers, all of them are aware of Syndication (100\%) and most of them $(80.0 \%)$ are aware of Media manipulation and Mashups, virtual world and online games, and blogging. Most of the instructors are using the following: media sharing (80.0\%), 
instant messaging and chat (60.0\%), and social networking (60.0\%). Most of these instructors don't use virtual world $(20.0 \%)$ and online games and syndication $(20.0 \%)$.

\begin{tabular}{|c|c|c|c|c|c|c|c|c|c|c|c|c|}
\hline \multirow[t]{3}{*}{ Tools } & \multicolumn{4}{|c|}{ Students } & \multicolumn{4}{|c|}{ Teachers } & \multicolumn{4}{|c|}{ As a whole } \\
\hline & \multicolumn{2}{|c|}{ aware } & \multicolumn{2}{|c|}{ using } & \multicolumn{2}{|c|}{ Aware } & \multicolumn{2}{|c|}{ using } & \multicolumn{2}{|c|}{ aware } & \multicolumn{2}{|c|}{ Using } \\
\hline & $f$ & $\%$ & $f$ & $\%$ & $f$ & $\%$ & $f$ & $\%$ & $f$ & $\%$ & $f$ & $\%$ \\
\hline 1 & 28 & 43.8 & 46 & 71.9 & 3 & 60.0 & 4 & 80.0 & 31 & 44.9 & 50 & 72.5 \\
\hline 2 & 37 & 57.8 & 34 & 53.1 & 4 & 80.0 & - & - & 41 & 59.4 & 34 & 49.3 \\
\hline 3 & 18 & 28.1 & 52 & 81.3 & 3 & 60.0 & 3 & 60.0 & 21 & 30.4 & 55 & 79.7 \\
\hline 4 & 35 & 54.7 & 31 & 48.4 & 4 & 80.0 & 1 & 20.0 & 39 & 56.5 & 32 & 46.4 \\
\hline 5 & 12 & 18.8 & 58 & 90.6 & 3 & 60.0 & 3 & 60.0 & 15 & 21.7 & 61 & 88.4 \\
\hline 6 & 41 & 64.1 & 26 & 40.6 & 4 & 80.0 & 2 & 40.0 & 45 & 65.2 & 28 & 40.6 \\
\hline 7 & 49 & 76.6 & 14 & 21.9 & 3 & 60.0 & - & - & 52 & 75.4 & 14 & 20.3 \\
\hline 8 & 26 & 40.6 & 43 & 67.2 & 3 & 60.0 & 2 & 40.0 & 29 & 42.0 & 45 & 65.2 \\
\hline 9 & 52 & 81.3 & 12 & 18.8 & 5 & 100.0 & 1 & 20.0 & 57 & 82.6 & 13 & 18.8 \\
\hline 10 & 42 & 65.6 & 24 & 37.5 & 3 & 60.0 & 3 & 60.0 & 45 & 65.2 & 27 & 39.1 \\
\hline $\begin{array}{l}\text { Mean } \\
\% \text { Score }\end{array}$ & & 53.14 & & 53.13 & & 70 & & 47.5 & & 54.33 & & 52.03 \\
\hline
\end{tabular}

Table 3:-Students' and Instructors' UNP LMS Tools Awareness and Usage

\section{Moodle.}

For the Moodle platform implementation,both instructors and students have a very high regardin the following: helping to support and improve communication between faculty and students $(\bar{x}=4.65)$; helping to minimize the academic workload of faculty $(\bar{x}=4.34)$; and enhancing the knowledge and understanding that students gain from lectures, tutorials, and practice $(\bar{x}=4.34)$. Like in the UNP LMS assessment, instructors also have average rating with regards to Moodleonly being utilized by technology-savvy students $(\bar{x}=3.38)$, prohibits students from developing their social skills $(\bar{x}=3.33)$, and teachers are unable to deliver courses and manage student effectively through Moodle $(\bar{x}=3.09)$.

\begin{tabular}{|c|c|c|c|c|c|c|c|c|c|c|c|c|}
\hline \multirow[t]{3}{*}{ Tools } & \multicolumn{4}{|c|}{ Students } & \multicolumn{4}{|c|}{ Teachers } & \multicolumn{4}{|c|}{ As a whole } \\
\hline & \multicolumn{2}{|c|}{ Aware } & \multicolumn{2}{|c|}{ using } & \multicolumn{2}{|c|}{ Aware } & \multicolumn{2}{|c|}{ using } & \multicolumn{2}{|c|}{ aware } & \multicolumn{2}{|c|}{ using } \\
\hline & $f$ & $\%$ & $f$ & $\%$ & $f$ & $\%$ & $f$ & $\%$ & $f$ & $\%$ & $f$ & $\%$ \\
\hline 1 & 40 & 62.5 & 49 & 76.6 & 4 & 80.0 & 4 & 80.0 & 44 & 63.8 & 53 & 76.8 \\
\hline 2 & 40 & 62.5 & 37 & 57.8 & 4 & 80.0 & 3 & 60.0 & 44 & 63.8 & 40 & 58.0 \\
\hline 3 & 32 & 50.0 & 49 & 76.6 & 4 & 80.0 & 3 & 60.0 & 36 & 52.2 & 52 & 75.4 \\
\hline 4 & 37 & 57.8 & 35 & 54.7 & 4 & 80.0 & 1 & 20.0 & 41 & 59.4 & 36 & 52.2 \\
\hline 5 & 32 & 50.0 & 56 & 87.5 & 3 & 60.0 & 3 & 60.0 & 35 & 50.7 & 59 & 85.5 \\
\hline 6 & 45 & 70.3 & 27 & 42.2 & 5 & 100.0 & 2 & 40.0 & 50 & 72.5 & 29 & 42.0 \\
\hline 7 & 47 & 73.4 & 22 & 34.4 & 3 & 60.0 & 1 & 20.0 & 50 & 72.5 & 23 & 33.3 \\
\hline 8 & 37 & 57.8 & 49 & 76.6 & 3 & 60.0 & 2 & 40.0 & 40 & 58.0 & 51 & 73.9 \\
\hline 9 & 49 & 76.6 & 13 & 20.3 & 5 & 100.0 & 1 & 20.0 & 54 & 78.3 & 14 & 20.3 \\
\hline 10 & 45 & 70.3 & 26 & 40.6 & 4 & 80.0 & 4 & 80.0 & 49 & 71.0 & 30 & 43.5 \\
\hline $\begin{array}{l}\text { Mean } \\
\% \text { Score }\end{array}$ & & 63.12 & & 56.73 & & 78 & & 48 & & 64.22 & & 56.09 \\
\hline
\end{tabular}

Table 4:-Students' and Instructors' Moodle Tools Awareness and Usage

Table 3 and Table 4 reveals the mean scores of Moodle tools awareness and usage survey all have a higher rating than of the UNP LMS's. The increases in the mean scores indicate that there has been an increase in awareness and usage of tools after the UNP LMS assessment was conducted considering the Moodle assessment happened at a latter time.As shown in Table 4, morestudents are now more aware of web technologies such as Syndication (76.6\%), Social Bookmarking (73.4\%), Blogging (70.3\%) and Online Forums (70.3\%). Students now use Social Networking (87.5.6\%), Media Sharing (76.6\%), Instant Messaging and Chat (76.6\%), and Wikis and Collaborative Editing Tools (76.6\%).Likewise, more instructorsare now more aware of the web technologies (78\%). Most of the instructors nowuse the following: media sharing $(80.0 \%)$, online forums $(80.0 \%)$, media manipulation and mashups $(60.0 \%)$, instant messaging and chat $(60.0 \%)$, and social networking $(60.0 \%)$. If we compare the overall mean scores 
between the implementation of UNP LMS and Moodle (as shown in Table 5), Moodlehas a higher overall mean $(\overline{\mathrm{x}}$ $=3.88)$ for implementation over UNP LMS $(\bar{x}=3.80)$. Furthermore, students prefer Moodle $(\bar{x}=3.89)$ over UNP LMS $(\bar{x}=3.85)$ as much as the instructors' favorable preference of Moodle $(\bar{x}=3.87)$ over UNP LMS $(\bar{x}=3.80)$.

\begin{tabular}{|c|c|c|c|c|c|c|}
\hline \multirow[t]{2}{*}{ Implementation } & \multicolumn{2}{|c|}{ Students } & \multicolumn{2}{|c|}{ Teachers } & \multicolumn{2}{|c|}{ Overall } \\
\hline & $\overline{\bar{x}}$ & DR & $\bar{X}$ & $\mathrm{DR}$ & $\overline{\bar{X}}$ & $\mathrm{DR}$ \\
\hline UNP LMS Overall & 3.85 & High & 3.75 & High & 3.80 & High \\
\hline Moodle Overall & 3.89 & High & 3.87 & High & 3.88 & High \\
\hline \multicolumn{7}{|l|}{ Note: } \\
\hline \begin{tabular}{|l|} 
Statistical Range \\
\end{tabular} & \multicolumn{3}{|c|}{ Item Descriptive Rating } & \multicolumn{3}{|c|}{ Overall Descriptive Rating } \\
\hline $4.21-5.0$ & \multicolumn{3}{|c|}{ Strongly Agree } & \multicolumn{3}{|c|}{ Very High } \\
\hline $3.41-4.2$ & \multicolumn{3}{|c|}{ Agree } & \multicolumn{3}{|l|}{ High } \\
\hline $2.61-3.4$ & \multicolumn{3}{|c|}{ Neutral } & \multicolumn{3}{|l|}{ Average } \\
\hline $1.81-2.6$ & \multicolumn{3}{|c|}{ Disagree } & \multicolumn{3}{|l|}{ Low } \\
\hline $1.0-1.8$ & \multicolumn{3}{|c|}{ Strongly Disagree } & \multicolumn{3}{|l|}{ Very Low } \\
\hline
\end{tabular}

Table 5:-Overall Students' and Instructors' perception on UNP LMS and Moodle

\section{Discussion:-}

Students and faculty both agree and have a very high regard about e-learning helping support and improve communication between faculty and students, and enhance the knowledge and understanding that students gain from lecturers.According to Falvo \& Johnson (2007), LMSs helps instructors and students discuss the course content by posting and responding to each other, maintaining student learning tracks, and managing learning activities in an online environment. All of the areas of both e-learning platform implementations were rated above average (average, high, or very high).In addition, both UNP LMS and Moodle platforms got high overall implementation ratings which denotes that both platforms are fulfilling its intended purposes. However, Moodle got a higher overall mean rating over UNP LMS indicating that students and faculty prefer Moodle over the UNP LMS.As suggested by Unal and Unal (2011), Moodle would be an effective alternative LMS to Blackboard and other LMSs because of its flexibility and open-source resource.In a comparison study of Ajlan and Zedan (2008) of different LMSs, Moodle, Desire2Learn, ANGEL learning management suite and SAKAI are shown to be the best with almost the maximum number of learner tools while Moodle has the least number of features. Along technical tools, Moodle was in the lead and the weakest products were KEWL and Claroline.Faculty and students have significant differences in opinion on the implementation between the UNP LMS and Moodle. Liaw et al. (2007) added that it is necessary to understand the target group in order to design effective e-learning environments and perceived enjoyment, and usefulness are positively related to the intention to use LMS.Conducting this research also increased the awareness and usage of faculty and students of web tools.Huffman and Huffman (2012) suggested that students utilizing the appropriate technological tool improved learning performance. With the application of these technologies, education will also become more user- centered and it will be more responsive to the needs of students, as it allows students to adjust and perform the educational programs as they need to (Virkus, 2008).

This study was primarily limited by its small sample size and it could have been expanded by including students and instructors from other colleges whereas the participants represented a narrow range of age. A larger and a more diverse sample would have benefited the results of this study. An improvement to this study could have been personally interviewing the instructors and students that could elicit a much more vast information regarding their attitude towards both e-learning implementations.

The researchers strongly recommends the change of e-learning platform based on the findings and conclusion. To improve LMS implementations, organizations need to consider the virtual learning environments to improve learning outcomes, ensure accessibility, and engage learners in user-friendly virtual learning environments (ON24 Inc., 2012). Also, an upgrade in the university web hosting is highly advised due to degradation of performance that is caused by Moodle in the shared hosting account.Policies and guidelines on the usage of e-learning should also be improved.

\section{References:-}

1. Al-Ajlan, A., \& Zedan, H. (2008). Why Moodle, in: 12th IEEE International Workshop on Future Trends of Distributed Computing Systems. pp. 58-64.Retrieved from http://goo.gl/VtYqVb 
2. Campus Computing Project's Campus Computing Survey 2010. Retrieved fromhttp://www.campuscomputing.net/summary/2010-campus-computing-survey

3. Falvo, D. A., \& Ben F., \& Johnson, B. F. (2007). The use of learning management systems in the United States. TechTrends. 51(2). 40-45.Retrieved from http://goo.gl/fkrSWn

4. Huffman, H. W., \& Huffman, A. H. (2012). Beyond basic study skills: The use of technology for success in college. Computers in Human Behavior, 28. 583-590. doi: 10.1016/j.chb.2011.11.004. Retrieved from http://goo.gl/OtKK8A

5. Liaw, S. S., Huang, H. M., \& Chen, G. D. (2007). Surveying instructor and learner attitudes toward e-learning. Computers Education, 49(4), 1066-1080.Retrieved from http://goo.gl/4XiWIo

6. ON24, Inc. (2012). Is your learning management system leaving your users dazed and confused? [Whitepaper]. Retrieved from http://goo.gl/5awN8D

7. Raga, R., Reyes, J.M., \& Buena, L. (2014). Perceptions and Utilization of a Blended Learning Implementation: An Analysis from Two Perspectives.Retrieved from http://goo.gl/B22U2W

8. Unal, Z., \& Unal, A. (2011). Evaluating and comparing the usability of web-based course management systems. Journal of Information Technology Education, 1019-1038.Retrieved from http://goo.gl/moht8c

9. Virkus, S. (2008). Use of Web 2.0 technologies in LIS education: experiences at Tallin University, Estonia. Program: Electronic Library \& Information Systems, 42(3), 262-274.Retrieved from http://goo.gl/wphQda. 